\title{
TEXTOS E METATEXTOS DE OSWALDO DE CAMARGO, LUIZ SILVA - CUTI E MÁRCIO BARBOSA PARA ENEGRECER OS MODOS DE SABER
}

\author{
Simone de Jesus Santos ${ }^{1}$
}

\section{RESUMO:}

O artigo é um recorte da dissertação Textos e Metatextos: escritos de Oswaldo de Camargo, Luiz Silva - Cuti e Márcio Barbosa (2010) propõe dar ênfase à relevância da Literatura Negra Brasileira para uma proposta de educação fundamentada na transformação social. Considerando que as hegemonias se contrapõem às afirmações de diferenças sociais e culturais de vários sujeitos, torna-se relevante o debate sobre o assunto. $\mathrm{O}$ procedimento metodológico de base exploratória e analítica de textos críticos e literários metalinguísticos dos autores em foco propiciou entender que Literatura Negra Brasileira é o espaço de onde negros(as) e brasileiros(as) enunciam o desejo de "suplementar" a "falta" de vozes que os contemplem no discurso literário nacional hegemônico.

Palavras-chave: Literatura Negra Brasileira. Sociedade. Transformação

RESUMEN: El artículo es un recorte de la disertación Textos y Metatextos: escritos de Oswaldo de Camargo, Luiz Silva - Cuti y Márcio Barbosa (2010) y propone dar énfasis a la relevancia de la Literatura Negra Brasileña para una propuesta de educación fundamentada en la transformación social. Considerando que las hegemonías se contraponen a las afirmaciones de diferencias sociales y culturales de varios sujetos, se hace relevante el debate sobre el asunto. El procedimiento metodológico de base exploratoria y analítica de textos críticos y literarios metalinguísticos de los autores en foco propició entender que Literatura Negra Brasileña es el espacio de donde negros y brasileños enuncian el deseo de "suplementar" a la "falta" de voces que los contemplan en el discurso literario nacional hegemónico.

Palabras- clave: Literatura Negra Brasileña. La sociedad. transformación

\footnotetext{
${ }^{1}$ Doutorado emEducação pela Universidade Federal da Bahia (UFBA). Mestrado em Educação pela Universidade Federal da Bahia (UFBA). Graduação em Letras Vernáculas pela Universidade Federal da Bahia. E-mail: sietnia@yahoo.com.br
} 


Faço de força
Meu verso
Fácil é feito de osso carne e sangue
e dum beliscão da Mãe Preta
Meu verso fala de negro
Meu verso fala de grito
que os brancos não escutaram
porque fecharam os ouvidos
Meu verso fala do ódio encolhido
Do nosso olhar esprimido
(CUTI, 1978,p.41)

O fragmento acima é parte do poema Meu verso de autoria do escritor negro Luiz Silva, oriundo da cidade de Ourinhos, em São Paulo, mais conhecido por seu pseudônimo Cuti. No excerto, observa-se a palavra negro, enquanto elemento sígnico de identidade, explicitamente oposta ao poder repressor de brancos racistas e temas - como as problemáticas advindas do racismo enfrentadas por negros(as) brasileiros(as) e suas afirmações identitárias negras - predominantes na tessitura linguística construída pelo escritor supracitado e por tantos outros(as) colaboradores(as) da diversidade de escritos reunidos sob a denominação de Literatura Negra Brasileira ou Literatura Afro-brasileira.

O debate de conceitos dessa produção, a partir de textos literários e críticos de seus autores, tornou-se meu motivo de estudo em minha dissertação de mestrado intitulada Textos e Metatextos: escritos de Oswaldo de Camargo, Luiz Silva - Cuti e Márcio Barbosa (2010), defendida na Universidade Federal da Bahia. Sendo assim, o presente artigo consiste num recorte da pesquisa realizada e meu intento é dar ênfase à relevância da Literatura Negra Brasileira para uma proposta de educação fundamentada na transformação social, numa perspectiva mais democrática e equitativa.

A respeito dos escritores em foco, destaca-se que Oswaldo de Camargo é um dos autores e críticos do texto literário elaborado por autores(as) negros(as). Nascido em 24 de Outubro do ano de 1936, na cidade de Bragança Paulista, no estado de São Paulo, é Jornalista, Publicitário, Compositor; atuou também na Imprensa Negra, publicou obras literárias individuais desde 1959, participa de antologias circulantes no Brasil e em outros países e é cofundador da coletânea Cadernos Negros.

Em depoimento concedido a mim, Luiz Silva - Cuti (2010,p.70) descreve a criação dos Cadernos Negros - que neste ano de 2018, atinge sua quadragésima edição ${ }^{2}$

\footnotetext{
${ }^{2}$ Vale dizer que há registros de lançamentos da quadragésima edição dos Cadernos Negros sendo realizados em diferentes cidades do Brasil: Piauí, Salvador, Brasília são algumas localidades.

Revista Educação e Ciências Sociais, Salvador, v.1, n.1, 2018.
} 
autofinanciada por seus(suas) participantes - e corrobora a publicação ininterrupta da antologia que reúne textualidades de autoria de negros e negras de distintos lugares do Brasil:

Em 1978, havia no Bexiga [...] uma entidade chamada Centro de Cultura e Arte Negra (CECAN). No CECAN se uniram pessoas muito ligadas às letras e dali nasceu a idéia de fazermos uma antologia que fosse capaz de publicar poemas e contos de outros negros. Inicialmente, a idéia nasceu comigo e com Hugo Ferreira e, em 1978, fizemos a publicação de um pequeno livro e já sabíamos que a série iria continuar.

Por sua vez, Cuti é o pseudônimo de Luiz Silva que nasceu em 31 de Outubro de 1951, na cidade de Ourinhos, em São Paulo. Cofundador da coletânea Cadernos Negros, apresenta ampla produção em gêneros literários diversos. Foi mantenedor da antologia citada e fundador do grupo Quilombhoje. ${ }^{3}$ Militante do Movimento Negro, sua primeira publicação data de 1978. Ele tem o título de Doutor em Letras pela Unicamp e seu último livro de poesias - Negrhúmus (2017) - foi publicado em 2017 e tive a honra de prefaciá-lo.

Por fim, Márcio José Barbosa nasceu em São Paulo, em 14 de Dezembro de 1959. Atual coordenador do Quilombhoje é responsável pela edição dos Cadernos Negros, junto com sua mulher Esmeralda Ribeiro. Possui experiências de militância e de desenhista. É autor de escritos sobre o Movimento Negro. Publica desde a edição nº 05 da já citada série e tem um romance de sua autoria.

O empenho na propagação do texto negro é um dos elos de convergência entre essas personalidades e suas iniciativas são direcionadas para o combate ao racismo, para a valorização da afirmação da identidade negra, para a associação de sujeitos negros interessados em ações destinadas à construção de uma sociedade mais justa e na qual respeita-se a diversidade. Esses contributos tornam-se inestimáveis para o contexto brasileiro e ao mesmo tempo, nem sempre ganham destaque nos mais diversos âmbitos de debate sobre o conhecimento, seja em produções bibliográficas como em livros didáticos, seja em instituições de ensino dos mais diversos segmentos.

Ao tratar dos expressivos esforços envidados por sujeitos negros em suas mobilizações, Clóvis Moura (1983) nos faz compreender que, a chamada abolição da escravatura - feita em último lugar pelo maior país da América Latina - juntamente com as premissas de modernização relegaram à marginalização a população negra. Esse fato nos faz atentar que tensões, conflitos, desafios gerados por ideologias racistas verificados constantemente em tempos recentes, vinculam-se a um cenário anterior cujas continuidades persistem.

\footnotetext{
${ }^{3}$ Grupo responsável pela edição dos Cadernos Negros desde 1983 e criado inicialmente para reunir negros e negras interessados(as) em discutir literatura. O termo Quilombhoje é um neologismo elaborado por Luiz Silva - Cuti.

Revista Educação e Ciências Sociais, Salvador, v.1, n.1, 2018.
} 
Nos dias de hoje, observamos, conforme diz Stuart Hall (2005), hegemonias contrapostas às afirmações de diferenças sociais e culturais de vários sujeitos. Portanto, é uma forma de repensarmos imaginários sociais de discriminação e almejarmos cumprimentos de efetivo exercício da cidadania para os mais diversos sujeitos, atentarmos para produções culturais que apontam para múltiplas estratégias engendradas por negros e negras preocupados(as) em valorizar diversidades culturais historicamente desprestigiadas pelas articulações do racismo e do(s) (neo)colonialismo(s) exibidos nas relações de poder. Nesse sentido, apresento aqui, parte da abordagem da Literatura Negra Brasileira em minha dissertação de mestrado cujo foco de estudo é a concepção dessa outro tecido literário a partir de textualidades críticas e artísticas elaboradas por alguns dos autores que a produzem: Oswaldo de Camargo, Luiz Silva - Cuti e Márcio Barbosa. As leituras teóricas e críticas desses escritores são por mim denominadas de Textos e aquelas de cunho literário são denominadas de Metatextos. O procedimento metodológico consistiu de base exploratória e analítica - fundamentado numa abordagem contemporânea da literatura, isto é, em diálogo com Estudos da Cultura, da Identidade e da Representação - por meio de leitura e exame do conceito de Literatura Negra Brasileira ou Afro-brasileira, com definições dos próprios escritores, em textos metalinguísticos, sejam teóricos e críticos, sejam literários: Textos e Metatextos. Para tanto, foram empregados, principalmente, conceitos teóricos de Dialogismo, Intertextualidade e Metalinguagem. Acredito nos elementos simbólicos apresentados no material em questão como contributo para a construção de uma sociedade antirracista e para a reelaboração de imagens sobre nós mesmos(as), nas quais gostamos de ser negros(as), nas quais gostamos de nossos fenótipos e nas quais nos posicionamos de modo contrário às perversidades geradas nas mais sutis atitudes racistas.

\subsection{AFIRMAÇÕES DE UMA LITERATURA NEGRA NA SOCIEDADE BRASILEIRA}

Na controvérsia de opiniões em que uns são a favor e outros contrários às expressões "literatura negra" ou "afro-brasileira," examinar noções dos autores sobre o tema interessa para elucidar o propósito de sua arte.

As primeiras análises sobre o assunto, no Brasil, foram construídas por Roger Bastide, na década de 1940. Em seu texto intitulado Poesia afro-brasileira consta um panorama significativo de escritores(as), mas o sociólogo francês argumenta que é inaceitável uma

Revista Educação e Ciências Sociais, Salvador, v.1, n.1, 2018. 
literatura afro-brasileira devido à inexistência, em território brasileiro, de uma linha jurídica de separação racial como ocorre nos Estados Unidos. Na concepção do sociólogo: “[...] no Brasil não existe barreira entre os homens, seja qual for a sua origem étnica." (BASTIDE, 1973,p.05) . E especificamente, acerca do trabalho literário de afrodescendentes afirma:

[...] no Brasil, onde não existem barreiras legais entre cidadãos desta ou daquela cor. Este fato, por isso mesmo justo e louvável, impede conflitos de que resultaram valores nossos e poderia ser apontado como um dos principais empecilhos à eclosão de uma poesia original afro-brasileira. (BASTIDE, 1973,p.05).

Em contrapartida, outras leituras como aquelas propostas por Abdias do Nascimento (1978), Jônatas Conceição da Silva (2004) acerca de contextos temporais mais próximos àquele levado em consideração pelo sociólogo francês, mostram que os conflitos, as violências decorrentes de relações étnicas e raciais em que negros e negras são subalternizados, inferiorizados são extremamente comuns no cotidiano brasileiro. Outrossim, em tempos mais recentes, pode-se apontar o recrudescimento de tragédias advindas do racismo:

No Brasil, sete em cada dez pessoas assassinadas são negras. Na faixa etária de 15 a 29 anos, são cinco vidas perdidas para a violência a cada duas horas. De 2005 a 2015, enquanto a taxa de homicídios por 100 mil habitantes teve queda de $12 \%$ para os não-negros, entre os negros houve aumento de 18,2\%. A letalidade das pessoas negras vem aumentando e isto exige políticas com foco na superação das desigualdades raciais Segundo pesquisa realizada pela Secretaria Especial de Políticas de Promoção da Igualdade Racial (SEPPIR) e pelo Senado Federal, 56\% da população brasileira concorda com a afirmação de que "a morte violenta de um jovem negro choca menos a sociedade do que a morte de um jovem branco". O dado revela como os brasileiros têm sido indiferentes a um problema que deveria ser de todos.

A campanha quer chamar atenção para o fato de que cada perda é um prejuízo para o conjunto da sociedade. Segundo dados recentemente divulgados pelo UNICEF, de cada mil adolescentes brasileiros, quatro vão ser assassinados antes de completar 19 anos. Se nada for feito, serão 43 mil brasileiros entre os 12 e os 18 anos mortos de 2015 a 2021, três vezes mais negros do que brancos. Entre os jovens, de 15 a 29, nos próximos 23 minutos, uma vida negra será perdida e um futuro cancelado. ( ONUBR, 2018, p.01)

Portanto, não se pode tratar das complexidades da sociedade brasileira ao prescindir dos impressionantes e alarmantes dados que apontam para a continuidade do histórico genocídio de negros e negras constitutivo da política colonial, reatualizado e persistente nos dias de hoje. Particularidades como essas, concernentes às populações negras no Brasil são presentificadas em produções textuais da Literatura Negra Brasileira, ou seja, são imagens plurais, em diálogo com as tensões, violências, histórias, subjetividades e diversidades de experiências de negros(as) que configuram outras faces da nacionalidade.

Revista Educação e Ciências Sociais, Salvador, v.1, n.1, 2018. 
Nessa esteira, a primeira seção da dissertação Textos e Metatextos: escritos de Oswaldo de Camargo, Luiz Silva - Cuti e Márcio Barbosa(2010) propôs a estabelecer o que denomino de diálogo tenso. Os aspectos homogêneo e heterogêneo, projetados respectivamente nas produções literárias canônicas e naquelas de escritores afro-brasileiros, conduziram-me a discutir especificidades das duas tradições: a literatura canônica brasileira articula-se ao construto de nacionalidade numa perspectiva supostamente homogênea e por seu turno, os textos afiliados à chamada literatura negra brasileira propiciam uma re-visão da identidade nacional. A literatura canônica é então entendida como um dos lugares onde o nacionalismo configura-se em imagens-textos.

Para o indiano Homi K.Bhabha (1998,p.206) um dos estudiosos da teoria póscolonialista, o nacionalismo deve ser distanciado de coesão ou unidade. Na sua concepção, o povo, categoria emblemática da nação, “ não se refere simplesmente a eventos históricos ou a componentes de um corpo político patriótico”, mas:

\begin{abstract}
tem de ser pensado num tempo-duplo, [...] consiste em 'objetos' históricos de uma pedagogia nacionalista, que atribui ao discurso uma autoridade que se baseia no preestabelecido ou na origem histórica constituída no passado; o povo consiste também em 'sujeitos' de um processo de significação que deve obliterar qualquer presença anterior ou originária do povo-nação para demonstrar os princípios prodigiosos, vivos, do povo como contemporaneidade, como aquele do signo do presente através do qual a vida nacional é redimida e reiterada como um processo reprodutivo .(BHABHA, 1998,p.206).
\end{abstract}

Nessa abordagem, contrapõem-se à história nacional, a perspectiva temporal descontínua da nação e o duplo lugar do povo, isto é, situado como "objeto" de uma pedagogia nacionalista que pretende afirmar uma "origem" e na postura de "sujeito" que pode desempenhar o seu próprio ato de "performance narrativa", como ilustra a fala de um personagem do Metatex to A descoberta do frio (1979) de autoria de Oswaldo de Camargo; trata-se de uma avaliação de um crítico literário no que diz respeito à poesia de Várzea de Mansidão, de autoria do personagem Antônio B. Jordão. Atentemos:

Você não conseguiu na Literatura, em prosa ou verso, ser mais do que um menino negro que tocasse oboé. Toca bem, mas dentro de uma estética que não é a sua e que você não teve coragem de ir buscar. Nada do que eu disser aqui é uma acusação, faço questão de frisar, mas uma constatação, a partir do meu ponto de vista, de minha forma de encarar a vida, é claro. Por isso, já tive a oportunidade de lhe dizer que quando o crítico, literato, esclareça-se, branco, agradou-se de sua obra, é porque ela está dentro de formas estéticas que não ferem seus padrões de julgamento. Logo, quanto mais agradar à crítica literária que domina a imprensa, equivale a dizer crítica branca, isto significa que mais distante você está de uma estética negra. E isso o crítico branco vê e acha bacana e lhe elogia por isso[...] (CAMARGO,1979,p.5659).

Revista Educação e Ciências Sociais, Salvador, v.1, n.1, 2018. 
O debate sobre o fazer literário compõe a narrativa e alude para a literatura canônica e para a não hegemônica, bem como para a existência da forma literária distanciada das performances inventadas por escritores(as) negros(as) e comumente desvalorizadas pela crítica dominante.

Entre a temporalidade continuísta "do pedagógico" e a "estratégia repetitiva" do performativo, instaura-se uma "cisão", a ambivalência de se escrever a nação. No tempo duplo, entre presente e passado ou caráter pedagógico e performativo do nacionalismo, instaura-se uma tensão no conceito de povo:

\begin{abstract}
A tensão entre o pedagógico e o performativo [...] na interpelação narrativa da nação converte a referência a um 'povo' - a partir de qualquer que seja a posição política ou cultural - em um problema de conhecimento que assombra a formação simbólica da autoridade nacional. O povo não é nem o princípio e nem o fim da narrativa nacional, ele representa o tênue limite entre os poderes totalizadores do social como comunidade homogênea, consensual, e as forças que significam a interpelação mais específica a interesses e identidades contenciosos, desiguais no interior de uma população. (BHABHA, 1998, p.207. Grifo meu)
\end{abstract}

Diferentes atos performativos do povo na contemporaneidade ou no tempo "presente" do Estado-nação denotam que ele, no lugar de "sujeito," gera tensão na temporalidade linear da narrativa nacional e em sua pedagogia que visa a ser reiterada e é revista quando as diferenças são postas em evidência como no Metatexto Denúncia de autoria de Luiz Silva Cuti:

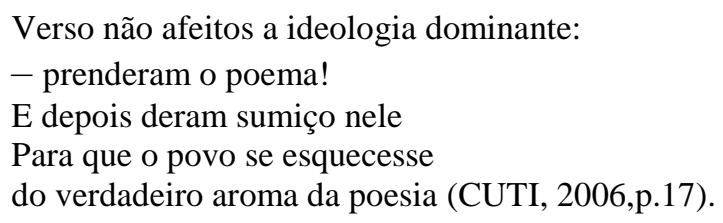

Nos versos acima, os textos que apresentam a expressão do eu poético negro e brasileiro são "presos," ou, impedidos de circular. Essa ação é para que o povo esqueça "o verdadeiro aroma da poesia," ou uma textualidade em que haja espaço para formas e linguagens mais populares. Forma/conteúdo em Textos e Metatextos de Luiz Silva - Cuti articulam-se entre si e com temas de circulação, recepção da crítica e do leitor. Portanto, na dupla temporalidade, passado e presente, no caráter pedagógico e performativo, há uma diversidade de enunciações dos indivíduos enquanto pertencentes a um determinado território nacional.

Assim, a Literatura Negra Brasileira expressa a diversidade étnica e racial encoberta pelo conjunto nacional simbólico "povo" e por isso, gera tensão em elementos construtores da comunidade nacional homogênea e consensual, como a literatura canônica brasileira Revista Educação e Ciências Sociais, Salvador, v.1, n.1, 2018. 
conforme expressam versos elaborados por Márcio Barbosa(2006,p.47) em Metatexto intitulado Manifesto Zero:

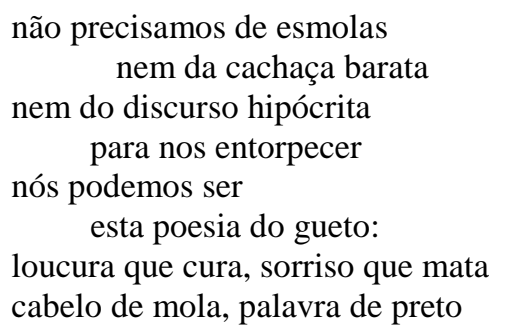

Nos versos acima, a literatura negra apresenta-se como aquela que recusa discursos dedicados a debilitar negros e negras, aliená-los(as), distanciá-los(as) da conscientização e da valorização positiva de si, através de instrumentos como a "cachaça" ou como o "discurso hipócrita" que nega a existência de uma desigualdade racial e para tanto, provém do "gueto" , e em seu jogo verbal é "a loucura que cura" e a "palavra do preto.

Geradora de tensão no discurso da brasilidade unívoca, a literatura negra e brasileira é uma das " [...] contra narrativas da nação que continuamente evocam e rasuram suas fronteiras totalizadoras - perturbam aquelas manobras ideológicas através das quais "comunidades imaginadas" (ANDERSON, 1989, p.15-16) recebem identidades essencialistas." As tessituras literárias que representam a diversidade étnica e racial do país, "rasuram" as "fronteiras totalizadoras" da identidade nacional, desestabilizam e criam tensão na pretensa uniformidade.

Muitos como um é "a metáfora progressista da coesão social moderna" e designa um sentido unívoco da nacionalidade. A literatura negra e brasileira distancia-se do ideal expresso na citada metáfora, não obstante, é parte dos textos artísticos produzidos no Brasil e gera tensão na pretensa homogeneidade nacional porque as imagens literárias elaboradas por negros(as) brasileiros(as) são entrecruzadas pela diversidade étnica e racial. Essa outra produção literária oportuniza-nos refletir sobre os cenários sociais que compõem os vários mosaicos das diferenças presentes no território brasileiro.

Joseph Ernest Renan ( 1990, p.18), em 11 de Março de 1882, na sua conhecida conferência intitulada Qu' est ce qu’ ne Nation? definiu que "não é a terra, mais que a raça, que faz a nação" (Tradução minha). Para ele, "a essência de uma nação é que todos os indivíduos tenham muitas coisas em comum e também que todos tenham esquecido muitas coisas." (Tradução minha).

Uma nação é:

Revista Educação e Ciências Sociais, Salvador, v.1, n.1, 2018. 
[...] uma alma, um princípio espiritual. Duas coisas que na verdade são uma, constituem esta alma ou princípio espiritual. Uma reside no passado, a outra no presente. Uma é a possessão em comum de um rico legado de memórias; a outra é o consentimento atual, o desejo de viver em conjunto, a vontade de perpetuar o valor da herança recebida de forma não dividida. (Tradução nossa). (RENAN, 1990,p.19).

Posteriormente, Benedict Anderson define a nação como uma comunidade imaginada:

A nação é imaginada como limitada, porque até mesmo a maior delas, que abarca talvez um bilhão de seres humanos, possui fronteiras finitas, ainda que elásticas, para além das quais encontram-se outras nações. Nenhuma nação se imagina coextensiva com a humanidade.[...]

É imaginada como soberana, porque o conceito nasceu numa época em que o Iluminismo e a Revolução estavam destruindo a legitimidade do reino dinástico hierárquico, divinamente instituído.[...] O penhor e o símbolo dessa liberdade o Estado soberano.

Finalmente, a nação é imaginada como comunidade porque, sem considerar a desigualdade e exploração que atualmente prevalecem em todas elas, a nação é sempre concebida como um companheirismo profundo e horizontal. (ANDERSON,1989,p. 15-16).

Ambas as concepções, seja como "princípio espiritual" vinculado ao "passado" e ao "presente," ou seja, como “comunidade imaginada", formuladas respectivamente por Joseph Ernest Renan e Benedict Anderson, explicitam que a consolidação da ideia de nação equivale a um construto.

Esse argumento é profícuo para a compreensão do empenho de negros(as) e brasileiros(as) na literatura que engendram. Significa trazer para a cena do debate "genealogias" (FOUCAULT,2004) de saberes, como aquelas ocultas pela história oficial, conhecimentos não situados nem acentuados enquanto integrantes do Estado-nação por parte de grupos dirigentes.

Movimento crítico semelhante às análises citadas acerca de nacionalismo faz-se necessário para com os modos de representação de afro-brasileiros(as) na literatura nacional e a sua repercussão - uma vez que, a nação pode ser compreendida como resultado de construções discursivas - para demonstrar a multiplicidade encoberta por essas últimas.

De acordo com Oswaldo de Camargo, há na literatura negra a "junção de":

poetas que [...] até onde sabemos jamais foram 'registrados' na história literária do Brasil. Pois é da obra de Caldas Barbosa, Luís Gama, Gonçalves Crespo, Cruz e Souza - negros - às correntes posteriores, com poetas negros e mulatos que se revelam negros, que escorre esta seiva poética, alento, reivindicação, consolo, e afirmação de que nós também somos Literatura.(CAMARGO, 1987, p.11-12)

Revista Educação e Ciências Sociais, Salvador, v.1, n.1, 2018. 
Já na visão de Luiz Silva - Cuti (1985,p.19), a "produção do negro brasileiro [...] por onde corre um pouco da interioridade negro-brasileira, tem se constituído numa resistência ao discurso dominante" e de acordo com Márcio José Barbosa ( 1983,p.121), são significativas para a "comunidade negra brasileira" associações culturais do "negro que cria o hábito de dirigir-se a outro negro[...] no sentido de destruir estruturas racistas" no país.

Essas afirmações denotam o intuito dos autores afro-brasileiros integrarem a história da literatura brasileira com os seus específicos discursos, resistirem a grupos dominantes e num movimento coletivo, empreenderem a "destruição" de "estruturas racistas" do contexto social no qual estão inseridos.

O crítico Alfredo Bosi $(1992$, p.68) acrescenta que a "[...]tradição de nossa literatura [...] teve sempre como um dos traços principais seu caráter "interessado" e a preocupação com o nacional." Essa sua opinião juntamente com a configuração da literatura canônica propiciam compreender a nacionalidade enquanto obsessiva inquietação da tradição literária brasileira. Não restringindo-se ao século XIX, em momentos posteriores a esse período, a mesma preocupação é incluída. Apesar dos questionamentos acerca da ênfase nas heranças coloniais pautadas em concepções estético literárias, a exemplo do Modernismo, o(a) afro-brasileiro(a) não ganha espaço prestigiado de representação. Em momento mais recente, Regina Dalcastagné (2010) mostra-nos que a personagem do romance brasileiro em fins de século XX é predominantemente branca.

Assim, a literatura brasileira auxilia no processo "pedagógico" pelo qual passa o povo na afirmação da nacionalidade porque participa dos discursos oficiais da nação. Favorece ao plebiscito diário, movimento duplo de lembrar e esquecer, desempenhado pelo indivíduo pertencente a uma nação, definido por Joseph Ernest Renan(1990). Portanto, as histórias as personalidades, os fatos, as experiências, os heróis reiterados nos espaços educativos e na sociedade como um todo não são aqueles representados nas produções literárias negras e se assim o fossem, teríamos uma alternativa de representações mais próximas de nossas identidades de descendentes de africanos(as).

\subsection{ENTRE INTERTEXTOS DA LITERATURA NEGRA BRASILEIRA}

Revista Educação e Ciências Sociais, Salvador, v.1, n.1, 2018. 
É possível caracterizar as tessituras artísticas em questão pela discordância, paródia, ironia, rasura, transgressão, subversão, inversão, reversão das imagens de afro-brasileiros(as) estereotipadas, "minimizadas", "negligenciadas" e instituídas na brasilidade.

A escritora afro-brasileira Maria Conceição Evaristo de Brito(2009, p.06) define:

\begin{abstract}
A literatura negra brasileira, ao apresentar um discurso outro que pretende uma autoapresentação do negro - discordante de um discurso de representação do negro produzido pela literatura dominante - vale-se da paródia como maneira de inverter, de subverter um discurso que, muitas vezes, ainda consagra o negro como res, coisa "ex-ótica" e que não cabe no campo de visão de um olhar viciado, limitado, que não compreende a alteridade, a não ser por um juízo de valor.
\end{abstract}

A assertiva da autora pode ser ilustrada quando lemos os Metatextos intitulados Atitude, Arremedo e O que não dizia o poeminha do Manuel: - de autoria de Oswaldo de Camargo, Luiz Silva - Cuti e Márcio Barbosa porque dialogam de modo crítico com a literatura hegemônica sob o olhar da Paródia e da Ironia.Na "estratégia performativa" da Literatura Negra Brasileira, em seu diálogo tenso com a produção oficial, torna-se imprescindível a criação de significações outras, distintas daquelas estabelecidas pelo texto literário da brasilidade.

No Metatexto Atitude, Oswaldo de Camargo parodia o poema intitulado Navio Negreiro de autoria de Castro Alves. Apresenta outra forma de "significar" o status escravo imposto ao negro e reescreve os versos consagrados:

\author{
atitude \\ Eu tenho a alma e o peito descobertos \\ à sorte de ser homem, homem negro, \\ primeiro imitador da noite e seus mistérios. \\ Triste entre os mais tristes, útil \\ como um animal de rosto manso. \\ Muita agonia bóia nos meus olhos, \\ inspiro poesia ao vate branco: \\ “...Stamos em pleno mar..." \\ Estamos em plena angústia! \\ $[\ldots]$ \\ tentamos criar um riso, \\ não riso para o senhor, \\ não riso para a senhora, \\ mas negro riso que suje \\ a rósea boca da aurora \\ e espalhe-se pelo mundo \\ sem arremedo ou moldagem, \\ e force os lábios tão finos \\ da senhorita Igualdade! \\ Estamos com a cara preta \\ Revista Educação e Ciências Sociais, Salvador, v.1, n.1, 2018.
}


rasgando a treva e a paisagem

minada de precipícios

velhos, jamais arredados!

$[\ldots]$

“...Stamos em pleno mar..."

Estamos em plena angústia!

Negro,ó negro, pedaço de noite, pe-

daço de mundo,ergue-te!

Deixa essa mansidão nos olhos,

tua delicadeza,

E o fácil riso jovial,

Sê duro, ó negro, duro,

Como o poste em que mil vezes te

chicotearam.

Sê negro, negro, negro,

Maravilhosamente negro!

(CAMARGO, 2010,p.43)

No início, O Metatexto parece reiterar o caráter passivo tão atribuído ao negro pelo colonizador devido à sua suposta aparência "triste" e de "animal de rosto manso." Esses aspectos constituem leit motiv da "missão" incumbida ao "vate branco." Porém, na sequência do repetido verso de Navio Negreiro: “...Stamos em pleno mar..."/ "Estamos em plena angústia" surge o sentimento de agonia. A "angústia" impulsiona "a atitude" daquele que busca um diferente retrato de si na história brasileira. O desejo de situar-se enquanto sujeito, distanciado do status de objeto do outro.

A transformação da "angústia" de um passado "triste" em "atitude" é o compromisso do eu poético associado a uma coletividade. "Criar um negro riso" que "suje a rósea boca da aurora" conota a busca do afro-brasileiro em inserir-se no devir da sociedade, sem quaisquer tipo de "arremedo" ou "moldagem". A ruptura com os "arremedos" ou "modelos" configura a recusa do exemplo do "vate", no qual o "rosto", ou melhor, o corpo do negro é "útil" e "manso".

O Metatexto Atitude, de autoria de Oswaldo de Camargo, evidencia que:

A transgressão oferecida pelos textos paródicos da literatura negra-brasileira pode ser observada nos textos em que a palavra literária vem reconstruindo a história. A literatura negra toma como parte do corpus a História do povo negro vivida e interpretada do ponto de vista negro, propondo uma leitura transgressora da História oficial e escrevendo a história dos dominados. (Grifos meus). (BRITO, 2009,p.0607).

Revista Educação e Ciências Sociais, Salvador, v.1, n.1, 2018. 
Oswaldo de Camargo subverte o discurso histórico literário hegemônico. Se o eu poético do texto romântico ficcionaliza o poder de mudar a história por parte do homem branco e europeu - "Andrada, Colombo" - o sujeito poético afro-brasileiro procura reverter o status do negro subalternizado. Na composição afro-brasileira, o negro é advertido a não adotar a suposta mansidão que inspira a poesia castroalviana e invés disso, é convidado a ser "duro", semelhante ao "poste em que mil vezes" o chicotearam.

Um dos Metatextos na autoria de Luiz Silva - Cuti ilustra a impossibilidade de as estruturas hegemônicas suplantarem as experiências dos sujeitos diferenciados. Os versos em Arremedo demonstram a transnegressão do cânone. Arremedos ou modelos de um sujeito determinado pela tradição eurocêntrica são rejeitados na poesia de Luiz Silva - Cuti:

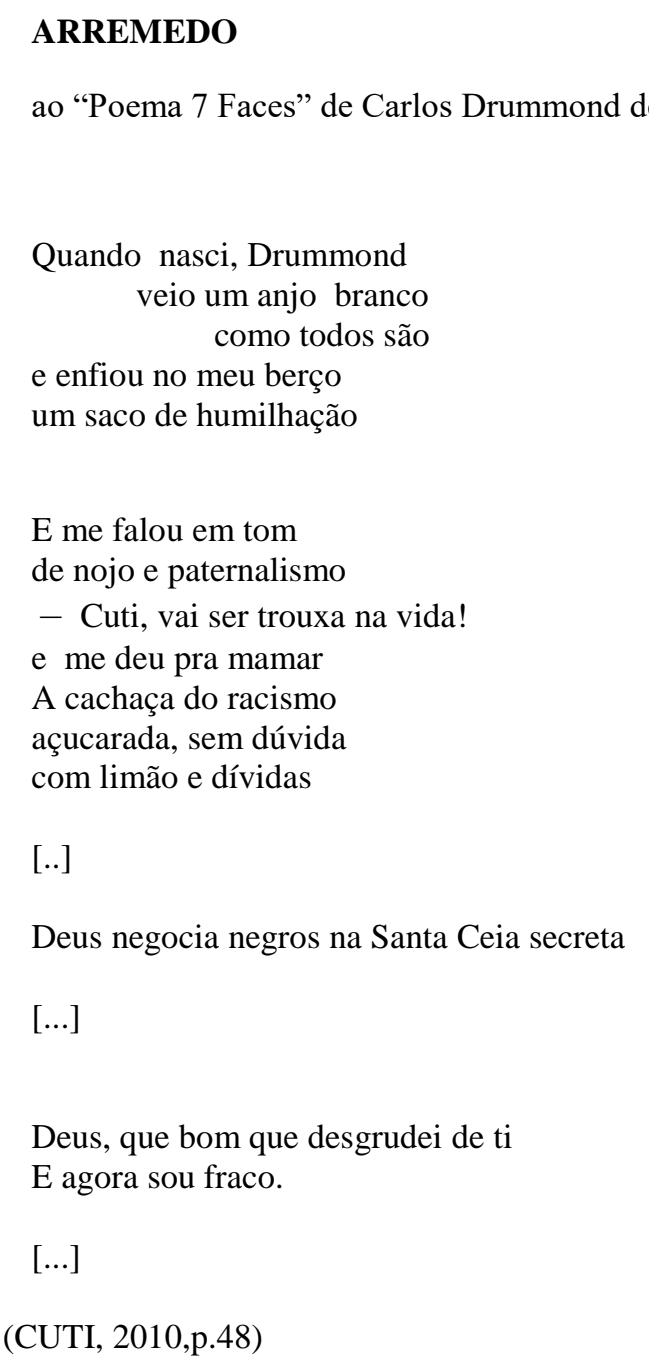

A intertextualidade é hábil e ironicamente configurada. Como substantivo, “arremedo" é sinônimo de cópia, imitação e, enquanto verbo, abrange sinônimos como reproduzir, imitar grotescamente.

Revista Educação e Ciências Sociais, Salvador, v.1, n.1, 2018. 
Os versos de Arremedo, contrapostos ao de Poema de sete faces, revelam outras "faces" de memória, nas quais a voz do eu poético deixa a sua crítica a valores cristãos, às práticas racistas e a um "lugar periférico" imposto ao negro na sociedade. Essa forma de "imitar grotescamente" e apresentar novas denotações nos remete à paródia, uma vez que nela "enuncia-se a fala recalcada do outro. Quando digo outro na acepção moderna: aquela visão social ou individual recalcada e que é preciso desentranhar para que se conheça o outro lado da vida". (Sant'anna,1998,p.29).

Por seu turno, Márcio José Barbosa observa esse aspecto quando parodia textos da literatura modernista brasileira, como expressa o Metatexto $\mathrm{O}$ que não dizia o poeminha do Manuel:

O que não dizia o poeminha do Manuel:

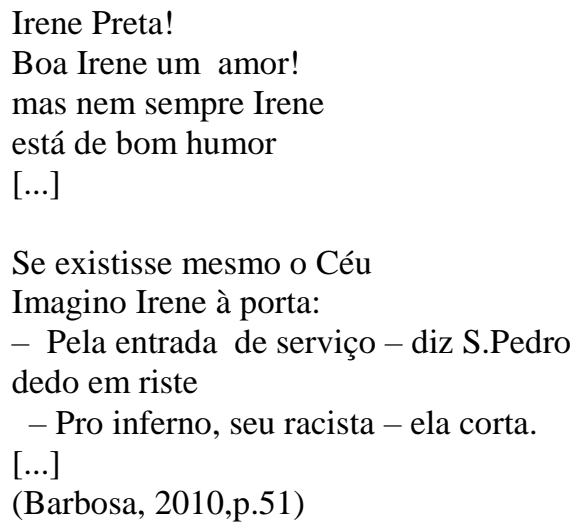

O poema de Manuel Bandeira denominado Irene é satirizado desde o título que o evoca como "poeminha do Manuel". O sufixo de diminutivo conota a redução do valor estético e temático apresentado pelo mesmo. Também, com a expressão "o que não dizia" alude-se para elementos de valor depreciativo acerca da mulher negra recalcados no texto canônico, relidos e expostos na tessitura da negrabrasilidade.

A representação e a escrita ficcional na autoria feminina negra é uma das preocupações de Márcio José Barbosa. Para ele “A mulher negra tem uma representação muito pequena em termos de quantitativo de escritores comparada com a representação masculina." (Barbosa, 1983, p.24).

Diferentemente dos versos de Manuel Bandeira, o Metatexto O que não dizia o poeminha do Manuel: interpreta e descarta a suposta passividade da mulher - a negra no poema Irene - e assim, "denuncia a [...] duplicidade, a ambiguidade e a contradição"( 
Sant'anna,1998,p.29) da composição canônica não abordadas pela crítica e história literárias oficiais.

\section{CONSIDERAÇÕES FINAIS}

Neste artigo, propus apresentar uma parte de minha dissertação intitulada Textos e Metatextos: escritos de Oswaldo de Camargo, Luiz Siva - Cuti e Márcio Barbosa(2010) cujo objetivo consistiu em investigar o conceito de Literatura Negra Brasileira. Os Textos e Metatextos dos autores propiciaram-me entender que a Literatura Negra Brasileira

\footnotetext{
é o lugar situado à margem da textualidade oficial brasileira. Espaço de onde afrobrasileiros(as) enunciam o desejo de "suplementar "à "falta" de vozes que os contemplem no discurso literário nacional hegemônico, inscrevem-se enquanto sujeitos na história e escrevem em textos ficcionais a diversidade cultural dos descendentes de africanos no Brasil. (Santos, 2010,p.167).
}

Nesse sentido, parte da pesquisa acadêmica aqui apresentada, propiciou verificar identidades culturais díspares nas respectivas textualidades citadas. Para além do escritos metalinguísticos, as dessemelhanças foram reiteradas nas interpretações dos escritores para textos canônicos. Ironia e paródia constituíram a intertextualidade que compreendi enquanto formas do que chamo de enegrecer os modos de saber. Entendo que informações a respeito dos afrodescendentes reapresentadas no texto artístico literário, se consideradas como explicitações, elucidações para eventos da sociedade brasileira podem significativamente renovar, alterar ou enegrecer, quero dizer, reler os discursos sobre os afrodescendentes no Brasil, a exemplo da literatura e da história nacionais.

Textos literários da Literatura Negra Brasileira se põem em intertextualidade com a história e assim, me propiciaram compreender, a partir da linguagem literária, outros modos de contar ou de reler a história do Brasil e essa ideia foi por mim apresentada em forma de Tese de Doutorado, defendida em 2015, na Universidade Federal da Bahia e intitulada Literaturas de histórias: contar outra vez narrativas de NegrAmérica com Manuel Zapata Olivella e Ana Maria Gonçalves(2015). Essa abordagem fundamenta-se, dentre outros conceitos, no pensamento liminar:

Minha discussão visa criar, através do pensamento liminar (isto é, pensamento situado entre as ciências humanas e a literatura) um arcabouço no qual a prática literária não seja concebida como objeto de estudo (estético, linguístico ou

Revista Educação e Ciências Sociais, Salvador, v.1, n.1, 2018. 
sociológico), mas como produção de conhecimento teórico[...] como reflexão à sua própria moda sobre problemas de interesse humano e histórico. (Mignolo, 2003, p.305).

Através da dissertação de mestrado em foco e de outras pesquisas que venho desenvolvendo sobre a Literatura Negra Brasileira, bem como através de prática docente e da atuação na formação docente, verifico que as produções literárias de negros e negras do Brasil consistem em espaço de diálogo de diferentes campos do saber onde linguagem, literatura, história, geografia e tantos outros conhecimentos vão sendo construídos em linguagem literária cuja subjetividade é de negros e negras. Tal protagonismo pode ser profícuo instrumento de práticas pedagógicas na perspectiva curricular, já que estudos de pesquisadores como Michael Apple (1982) sustentam que o espaço do currículo é também um espaço de poder. A Literatura Negra pode Enegrecer os Modos de Saber e apresentar conhecimentos nem sempre valorizados e difundidos nas práticas curriculares e colaborar para uma ruptura e uma revisão para com a "tradição seletiva" de conhecimentos hegemônicos no âmbito pedagógico ${ }^{4}$ - nos mais diversos níveis de ensino. Creio que seja esse um dos caminhos para vislumbrarmos a educação como um mecanismo de formação e de contributo para a transformação de mundos.

\section{REFERÊECIAS:}

ANDERSON, Benedict. Nação: consciência nacional. São Paulo: Ática, 1989.

APPLE, Michael. Ideologia e Currículo. São Paulo:Brasiliense, 1982.

BARBOSA, Márcio. O sentido da literatura negra, sob uma abordagem fanoniana. In: Criação crioula, nu elefante branco. 1983.

Manifesto $\mathrm{n}^{\mathrm{o}}$ zero. In: BARBOSA, Márcio José; RIBEIRO, Esmeralda(Orgs.) Cadernos Negros 29:poemas afrobrasileiros. São Paulo: Quilombhoje, 2006.

. O que não dizia o poeminha do Manuel. In: SANTOS, Simone de Jesus. Textos e Metatextos: escritos de Oswaldo de Camargo, Luiz Silva - Cuti e Márcio Barbosa. 2010. 161 folhas. Dissertação ( Mestrado). Centro de Estudos Afro-Orientais. Faculdade de Filosofia e Ciências Humanas. Universidade Federal da Bahia. Salvador, 2010.

\footnotetext{
${ }^{4}$ Venho inserindo produções da Literatura Negra Brasileira em minhas práticas pedagógicas em sala de aula, nos mais diferentes níveis de ensino e verificado que trata-se de uma textualidade que contribui significativamente, de modo positivo, para o fortalecimento das identidades negras. Outrossim, as pesquisas acadêmicas por mim realizadas sobre o tema me propiciaram criar a iniciativa Curso de Formação Continuada Literatura Negra para Enegrecer os Modos de Saber apoiada pelo Governo do Estado e pelo Centro de Estudos dos Povos Afro- Índio Americanos da Universidade Estadual da Bahia.

Revista Educação e Ciências Sociais, Salvador, v.1, n.1, 2018.
} 
BASTIDE, Roger. Poesia Afro-brasileira. In: Estudos Afro-brasileiros. São Paulo: Perspectiva, 1973.

BHABHA, Homi K. O local da cultura. Belo Horizonte: Editora UFMG, 1998.

BOSI, Alfredo. História concisa da Literatura Brasileira.2. ed. São Paulo: Companhia das Letras, 1992.

BRITO, Maria da Conceição Evaristo de. Literatura Negra: uma voz quilombola na Literatura $\quad$ Brasileira. $\quad$ Disponível em <bibliotecavirtual.clacso.org.ar/ar/libros/aladaa/evaris.rtf.> . Acesso em 07/2009.

CAMARGO,Oswaldo. A descoberta do frio: novela.São Paulo: Populares.1979.

. O negro escrito: apontamentos sobre a presença do negro na Literatura Brasileira. São Paulo, 1987.

Atitude. In: SANTOS, Simone de Jesus. Textos e Metatextos: escritos de Oswaldo de Camargo, Luiz Silva - Cuti e Márcio Barbosa. 2010. 161 folhas. Dissertação ( Mestrado). Centro de Estudos Afro-Orientais. Faculdade de Filosofia e Ciências Humanas. Universidade Federal da Bahia. Salvador, 2010.

DALCASTAGNÉ, Regina. A personagem do romance brasileiro contemporâneo:1990-2004. Disponível em www.periodicos.unb.br . Acesso Outubro/2009.

FOCAULT, Michael. Verdade e poder. In: Microfísica do poder. 2004. Disponível em <www.sabotagem.cjb.net>. Acesso em 09/2007.

HALL, Stuart. A questão multicultural. In: Da diáspora: identidades e mediações culturais. Tradução Adelaine La Guardia Resende... [et al.]. Belo Horizonte: Editora UFMG, 2003.

MOURA, Clóvis. Brasil: as raízes do protesto negro. São Paulo: Global Editora,1983.

MIGNOLO, Walter. Histórias locais/projetos globais: colonialidade, saberes subalternos e pensamento liminar. Tradução de Solange Ribeiro de Oliveira. Belo Horizonte: Editora UFMG: 2005.

NASCIMENTO, Abdias do. O genocídio do negro brasileiro: O processo de um racismo mascarado. Rio de Janeiro: Paz e Terra, 1978.

RENAN, Joseph Ernest. What is a nation? In: BHABHA, Homi K. Nation and Narration. London: Routledge, 1990.

SANT’ANNA, Affonso Romano de. Paródia, Paráfrase \& Cia. 3 ed. São Paulo: Ática,1998.

SANTOS, Simone de Jesus. Textos e Metatextos: escritos de Oswaldo de Camargo, Luiz Silva - Cuti e Márcio Barbosa. 2010. 161 folhas. Dissertação de Mestrado. Centro de Estudos Revista Educação e Ciências Sociais, Salvador, v.1, n.1, 2018. 
Afro-Orientais. Faculdade de Filosofia e Ciências Humanas. Universidade Federal da Bahia. Salvador, 2010.

SILVA, Luiz. Meu verso. In: Cadernos Negros 1: poesia. São Paulo: Edição dos(as) autores(as), 1978.

São Paulo, 1985.

Literatura Negra Brasileira: notas a respeito de condicionamentos. In: Reflexões.

Denúncia.In:

Negroesia. Belo Horizonte: Mazza, 2006.

Arremedo. In: SANTOS, Simone de Jesus. Textos e Metatextos: escritos de Oswaldo de Camargo, Luiz Silva - Cuti e Márcio Barbosa. 2010. 161 folhas. Dissertação (Mestrado). Centro de Estudos Afro-Orientais. Faculdade de Filosofia e Ciências Humanas. Universidade Federal da Bahia. Salvador, 2010.

Depoimento concedido pelo autor. In: SANTOS, Simone de Jesus. Textos e Metatextos: escritos de Oswaldo de Camargo, Luiz Silva - Cuti e Márcio Barbosa. 2010. 161 folhas. Dissertação (Mestrado) - Centro de Estudos Afro-Orientais. Faculdade de Filosofia e Ciências Humanas. Universidade Federal da Bahia. Salvador, 2010.

SANTOS, Simone de Jesus. Literaturas de histórias: contar outra vez narrativas de NegrAmérica. 2015. 223 folhas. Tese ( Doutorado) - Instituto de Letras. Universidade Federal da Bahia, Salvador, 2015.

SILVA, Jônatas Conceição da. Vozes Quilombolas: uma poética brasileira. Salvador: Edufba: ILÊ AIYÊ, 2004.

Vidas Negras - Pelo fim da violência contra a juventude negra no Brasil. Disponível em https://nacoesunidas.org/vidasnegras/. Acesso: Abril/2018

Revista Educação e Ciências Sociais, Salvador, v.1, n.1, 2018. 